\title{
Porta Optica - optical gateway to GÉANT2
}

\author{
Artur Binczewski, Michal Przybylski \\ Maciej Stroiński, Jan Węglarz \\ Poznań Supercomputing \& Networking Centre, ul. Noskowskiego 12/14 Poznań, 61-704 Poland \\ e-mail: $\{$ artur $\mid$ michalp|stroins $\mid$ weglarz\}@man.poznan.pl
}

\begin{abstract}
Dark fibre networks are considered the key element of future research infrastructures. The ownership of fibre leads to the freedom of development, freedom of choice of technology and freedom of design for research networks, as well as virtually unlimited transmission capacity. This concept has been confirmed by the new design of the GÉANT2 [1] network, where majority of links will be based on dark fibre. At the same time, while the GÉANT2 network has been upgraded to a level of technology that allows multiple $10 \mathrm{Gbit} / \mathrm{s}$ connections between most of the GÉANT2 partners, many countries of Eastern Europe are still suffering from insufficient connectivity to the Internet. It is expected that a strong role in the development of pan-European research network can be played by so called "Cross Border Fibres" (CBF), owned and operated by NRENs. This paper provides an overview of the PIONIER infrastructure and the Porta Optica initiative, which aims to improve the connectivity of Eastern European NRENs to GÉANT2, using a CBF infrastructure.
\end{abstract}

Key words: Porta Optica Study, Cross Border Fibres, GÉANT2, Eastern Europe

\section{INTRODUCTION}

Porta Optica - the distributed optical gateway to GÉANT2, is the result of an ongoing, five year experiment started in Poland in 2000. Then, due to the miserable infrastructure and the lack of competition (caused by a highly monopolised and regulated market) the Polish research community took the decision to build its own fibre optic infrastructure, able to satisfy the demands of science for the next twenty-plus years. This activity of development of the infrastructure has been included in the PIONIER programme (Polish Optical Internet - Advanced Applications, Services and Technologies for the Information Society) [2].

At that time, this initiative was considered revolutionary and raised many doubts and questions within the research community of Europe. We can now say that after five years of the construction process, the Polish research community has access to a leading-edge transmission infrastructure, with current transmission capacities matching those of GÉANT2 and other leading research networks in the world. Actually, with $10 \mathrm{Gbit} / \mathrm{s}$ transmission, twentyone cities connected and over $3000 \mathrm{~km}$ fibre lines available, this is the largest NREN-owned infrastructure of this type in the world.

The construction of the national fibre network has been a success and has raised much attention in Europe - several National Research and Education Networks (NRENs) have already acquired the fibre and installed high-capacity transmission equipment, moving from the leased channels to an own-infrastructure model. Several others are also planning to follow that example. The construction of such networks dramatically changed the research networking landscape in the countries involved, but at the same time, also increased the digital divide seen between the fibre-based networks of Western Europe and the legacy, low-speed, leased channel-based networks of Eastern Europe. The distinction here is significant in network coverage, in speed and in international access.

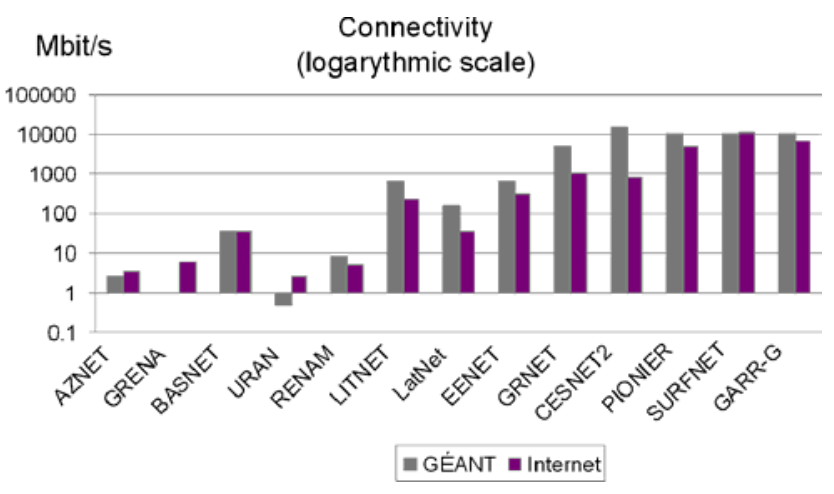

Fig. 1. The access speeds of different countries

This situation is depicted on Fig. 1. It shows very clearly that the networks based on fibre (CESNET2, SURFnet, PIONIER) are far ahead, with the capacities exceeding by a thousand times the capacity of the networks of Ukraine, Belarus, Azerbaijan or Moldova that are based on telecom channels, in highly monopolised markets. This 
unfortunate situation influences all areas of science that depend on the access to affordable, reliable and robust communication channels. Further, it creates obstacles to the collaborative work and related work environments, such as Grids. We will show how to level such differences by exploiting the potentials of the new infrastructure of the highly-developed NRENs.

\section{PIONIER AND ITS USABILITY FOR GÉANT2 - EXTENSIONS TO THE EAST}

PIONIER is an optical national research network connecting twenty-one fibre-based academic Metropolitan Area Networks (MANs) and five High-performance Computing Centres. The construction of the PIONIER network started in 2000, as the result of the PIONIER programme, announced in 1999 by the State Committee for Scientific Research. The programme assumed that the new "advanced networking infrastructure" (i.e., an optical, terabit, scalable fibre network) connecting all education and research centres in Poland had to be built in order to provide a platform for advanced applications and research infrastructures. network has started in 2001 and DWDM technology was identified as the appropriate transmission solution. As the quantity and quality of the fibres offered by telecom operators were not satisfactory for the current and future demands of advanced optical networking, the decision was taken to build new fibres with the co-operation of the telecommunication carriers, using a cost-sharing model.

As the result of these actions, PIONIER can boast $2763 \mathrm{~km}$. of active fibre lines, $1286 \mathrm{~km}$. of fibre lines under construction and $1159 \mathrm{~km}$. contracted for end of 2006. The number of available fibres varies, depending on the location; usually $12 \times$ G.652 and $4 \times$ G.655 fibres are available on each link.

The availability of fibre allowed for significant improvement to the backbone transmission speed - since June 2003, sixteen MANs situated along installed fibres are equipped with a $10 \mathrm{Gbit} / \mathrm{s}$ DWDM transport system with overlaying a 10GE transmission network. The general model of service provisioning is based on VLANs offered by 10GE technology. The target PIONIER network will use multi-lambda technology $(10-40 \mathrm{Gbit} / \mathrm{s})$ where individ-

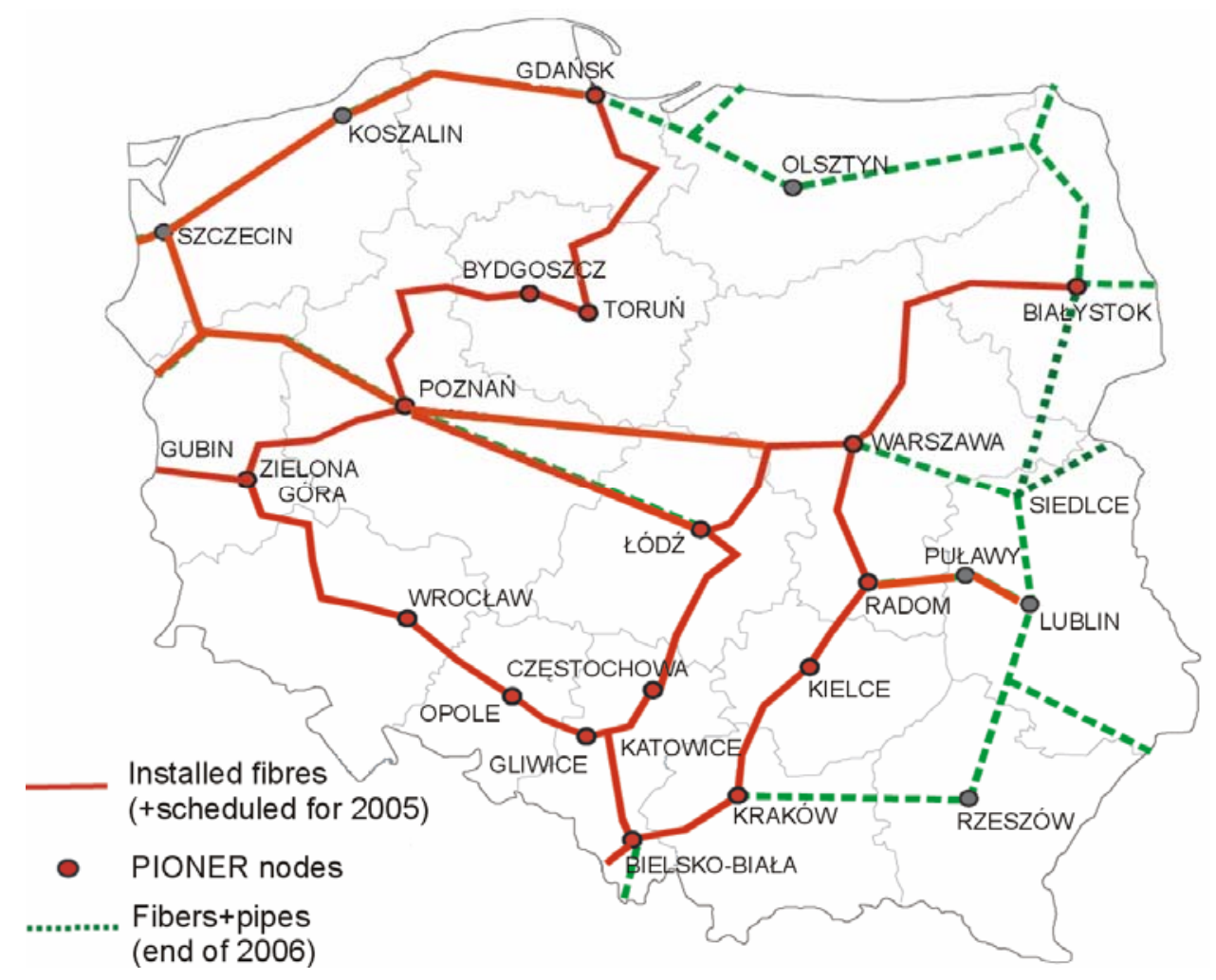

Fig. 2. The status of PIONIER fibres

After several experiments with the new generation of transmission equipment (using Dense Wavelength DivisionMultiplexing - DWDM), the deployment of the PIONIER ual lambdas will be used for the construction of different, dedicated networks. In fact, this network will be an Intelligent Optical Network, where the security and reliability is 
realised at lambda- and fibre-level. The architecture and the number of network layers will be simplified by using $10 \mathrm{GE}$ (or $n \times 10 \mathrm{GE}$ ) technology directly over lambda or fibre.

Due to the distinctive features of the PIONIER network, compared to other NRENs, PIONIER can be considered an important and unique part of the pan-European research networking infrastructure. Its special purpose will be the linking of Eastern European NRENs to GEANT2. There are several facts that allow such judgment:

- More than one fibre-pair in a link.

Depending on the year of the deployment, some lines are composed of the fibres in the shared cable (pre-2004).In this case, there are usually $12 \times$ G. 652 and $4 \times$ G.655 fibres available on each link. From 2005, all new fibre lines are built using own-cable in own-pipe, with one spare pipe for future developments. In this case, the link is composed of $18 \times$ G.652 and $6 \times$ G.655 fibres. The availability of spare fibre makes it possible to offer them for GÉANT2 connectivity, also with a diverse-route feature and if necessary, without disturbing the NREN infrastructure.

- The availability of a CBF fibre on virtually every national border.

There is a fibre line installed or under construction to every neighbouring country, including three separate links to Germany and one each to Czech Republic, Slovakia, Ukraine, Belarus, Lithuania and Russia (Kaliningrad Region). One of the links - to Czech Republic - is already equipped with transmission equipment and now operates with a speed of $1 \mathrm{Gbit} / \mathrm{s}$ in Ethernet technology and provides the link to the research networks: CESNET (Czech Rep.), SANET (Slovakia) and ACONET (Austria). This is a part of the largest completely NREN-owned, CBF infrastructure in Europe. Such CBF links can be used to provide direct connectivity to neighbouring countries without the need to procure additional international capacity from telecom operators.

- The availability of DWDM transmission in the national backbone.

Such systems allow the transportation of more than one high-capacity client signal in a transparent way across the network. Dedicated channels for transit to GÉANT2 can be setup quite easily for the support of neighbouring countries, if this is more feasible than using separate fibre.

- The topology of national backbone and CBF locations allows for various protection schemes to be applied on the fibre and transport layer, for enhanced network reliability.

\section{THE PORTA OPTICA INITIATIVE}

The possession of fibre is extremely important for every NREN, as it offers freedom, sustainability and predictive operating costs. Fibre-based NRENs have flexibility of network design and technology choice. Such networks ensure a fixed cost for the use of the infrastructure and at the same time, provide scalability up to Tbit/s, as the users' demands grow. The transmission capacities and the range of the infrastructure of the NRENs that already recognised these benefits (such as PIONIER, CESNET, SANET) have rocketed.

Unfortunately, the "digital divide" is clearly visible at the eastern and south eastern borders of European Union (EU). The very expensive, kilobit-and megabit-capable networks of eastern states (mainly based on communication channels provided by local telecoms) are no match for multi-gigabit networks of EU countries (usually based on own dark-fibre infrastructure or relatively cheap, high capacity channels procured from telecoms). In this situation, EU research teams are virtually cut-off from potential nonEU partners in the region, simply because of the limitations of the research networking infrastructures in Eastern Europe.

The above observations are confirmed by the relevant study of SERENATE [3] project, which concludes that:

- the digital divide exists in research networking in Europe and to such a level that, if uncorrected, will prevent the goal of equal opportunities for researchers being attained;

- in the countries most affected by the digital divide, the case for effective government support for research networking still needs to be made. This is an area where the European Commission, national governments, TERENA and the NREN community all need to play their part;

- we conclude that research exclusion is a real risk in most of the neighbouring countries and that this will obstruct attempts to build the European Research Area [4].

This situation leads to a widely held belief, that only dark fibre infrastructures, when owned by NRENs, can help to bypass the disadvantages related to local conditions (such as poor market development, insufficient funding etc.) and bridge the gaps between various, very demanding research communities, such as radio astronomy, high energy physic and grids

This is also confirmed by the recommendations included in SERENATE reports:

- if an NREN can get access to dark fibre, then it can, within the same budget, immediately upgrade the network capacity by as much as a factor of 100 ;

- participation in joint projects has been helpful to the NRENs in neighbouring countries (...) For these countries, a small amount of funding could make a large difference;

- the EU should, in particular help to persuade national governments that NRENs should get access to dark fibre [4].

The PORTA OPTICA initiative has been proposed as the first step towards the development of high-capacity research networks in Eastern European states and their integration with European infrastructures, such as GÉANT2. The initiative has been recognised by Armenia, Azerbaijan, Belarus, Estonia, Georgia, Latvia, Lithuania, Moldova, Slovakia and Ukraine. 
PORTA OPTICA aims at support of development of fibre for NRENs in the countries involved, and in interconnection between themselves and to the GÉANT2 network using the infrastructure and expertise of PIONIER, CESNET, SANET and other more developed NRENs.

Under this umbrella, the first step towards consolidating the related initiatives has been made as the proposal of a Porta Optica Study. This project, in particular will initiate the following activities:

- identification of potential beneficiaries of NREN services - the user base, users location and requirements, with the focus on user communities with potential to collaborate with EU partners (such as High Energy Physics, astronomy etc.);

- identification of possibilities for constructing fibrebased NRENs and their interconnection to GÉANT2 including market conditions and funding opportunities;

- case studies resulting in deployment scenarios for dark fibre infrastructure;

- raising the awareness and dissemination of the project ideas and results in order to achieve critical mass necessary to enable future deployments of fibre infrastructures. effectively reducing the digital divide. For that purpose, the Porta Optica Study will exploit the synergy resulting from cooperation with GEANT2 and the SEEREN[5]/SEEFIRE[6] projects, where similar approaches are now being implemented. The Porta Optica Study will collaborate with Eastern Europe NRENs, user communities and dark fibre providers in order to enable further development of broadband research networking in the region.

The Porta Optica initiative is directly supported by the concept of e-Regions; this is small, regional communities, usually located on both sides of national borders exploiting the benefits of advanced networking infrastructures connecting academic cities. e-Region is defined as a quantum unit of the e-Europe and e-World idea. In the complicated, multinational and multilingual European landscape, regional cooperation is seen as a trigger for deeper, global transformation.

The main objectives of e-Region are formulated as follows:

- creation of a rational base and the possibility of integrated work between institutions across the border, as defined by e-Europe in the area of education, medicine, natural disasters, information bases, protection of environment;

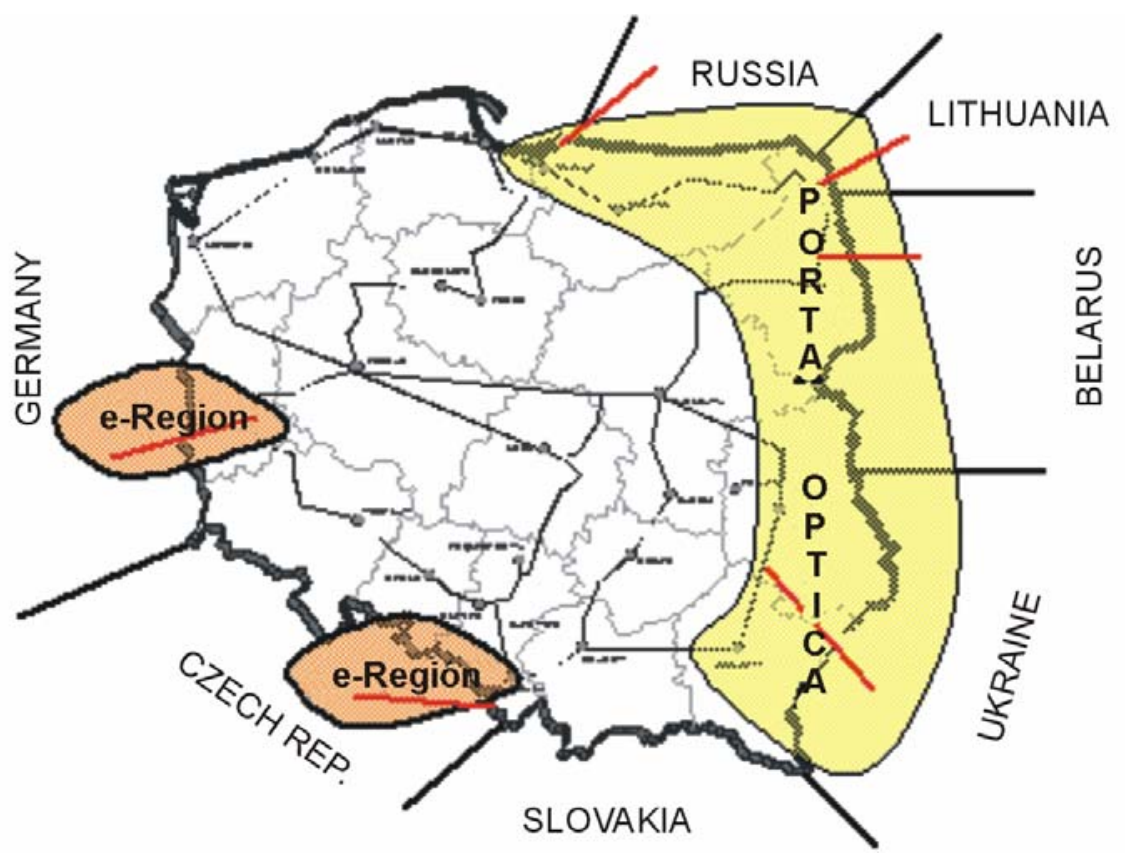

Fig. 3. e-Region and Porta Optica as a quantum unit of e-Europe

The Porta Optica Study partners believe that targeted states have a great opportunity to match the developments of Western Europe countries. This opportunity stems from the fact that NRENs in some of these countries are still being developed, thus are open for cooperation both on national and on the pan-European level. In some cases, they may be considered a "green field" situation, where well-proven European concepts can easily be introduced,
- enhancement of the ability for co-operation by developing a new generation of services and applications;

- promotion of the region in Europe (as a micro scale of e-Europe concept).

Currently there are several e-Region activities already started in Poland - one is located at the Polish-German border (connecting partnering universities in Cottbus and Zielona Góra) and another one on Polish-Czech border 
(Ostrava and Bielsko Biała). There is also planned e-Region with Slovakia.

\section{CONCLUSIONS AND FUTURE WORK}

We can conclude this document by a set of statements, which reflect the current state of activities related to the development of Eastern European research networks and their interconnection with GÉANT2.

- The PIONIER network is prepared to support the interconnection to GÉANT2 for Eastern European states using cross-border fibres.

- The connectivity of Belarus to the world Internet has been provided using PIONIER resources and has increased by seventeen times (from 2 to $34 \mathrm{Mbit} / \mathrm{s}$ ). There are now talks to build/rent the fibre between PIONIER and Minsk. - The Ukraininan research network UARNET is already building a fibre link from Kiev to Lviv and to PIONIER network.

- The Kaliningrad region of Russia is also planning the construction of fibre to the PIONIER network.

- The CBF connection is intensively used between PIONIER, CESNET, SANET and ACONET.

- The model of the CBF operations has been embedded in the GÉANT2 JRA4 activity for further investigation as the model for future pan-European research networks.

- The Porta Optica Study proposal is currently in the negotiation phase.

The above statements confirm the usability of the PIONIER fibre infrastructure for the interconnection of Eastern European NRENs to GÉANT2. There is clear evidence of the influence of the successful development of national fibre network on the development plans of Eastern European NRENs. The works of the Porta Optica Study will provide the necessary technical and financial guidelines for dark-fibre NREN deployments in the region.

\section{References}

[1] GEANT2 website: http://www.geant2.net

[2] PIONIER website: http://www.pionier.gov.pl/eindex.html

[3] SERENATE website: http://www.serenate.org

[4] M. Bonac, J. Martin, SERENATE, Deliverable D16, Report identifying issues related to the geographic coverage of European research and education networking. http://www.serenate.org/publications/d16-serenate.pdf

[5] SEEREN website: http://www.seeren.org

[6] SEEFIRE website: http://www.seefire.org

[7] M. Nakonieczny, S. Starzak, M. Stroiński, J. Węglarz, Polish scientific broadband network: POL-34, Computer Networks and ISDN systems 30 (1998) 1669-1676.

[8] PIONIER: Polish Optical Internet - Advanced Applications, Services and Technologies for Information Society, September 2000, http://www.kbn.gov.pl/en/pionier/index.html

[9] A. Binczewski, N. Meyer, J. Nabrzyski, S. Starzak, M. Stroiński, J. Węglarz, First experiences with the Polish Optical Internet, Computer Networks 37 (2001) 747-759.

[10] A. Binczewski, M. Przybylski, M. Stroiński, Next Generation Network - a PIONIER example, TERENA Networking Conference 2003, Zagreb, 19-22.05.2003.

[11] N. Meyer, M. Stroiński, J. Wegglarz, Optical Network for Euroregional co-operation, Proceedings of the Polish-German Symposium on Science Research Education, SRE 2000.

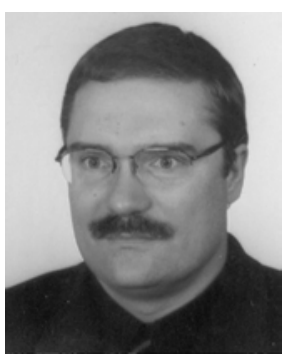

ARTUR BINCZEWSKI received an M.Sc. degree in Computer Science from the Poznan University of Technology in 1993. His research interests concern computer networks, routing, multicasting and management. He is the Manager of Network Division at the Poznan Supercomputing and Networking Center. Hi was involved in in several EC projects: SEQUIN (IST-1999-20841), ATRIUM (IST-1999-20675), 6NET (IST2001-32063) and others. His research interests concern computer networks protocols and management. He is author or co-author of papers in major professional journals and conference proceedings. He takes an active part in the development of PIONIER fiber network.

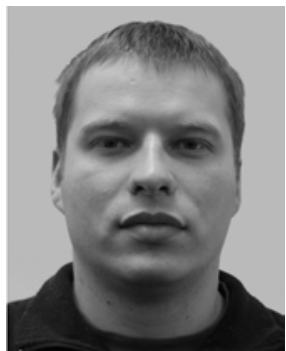

Michal Przybylski received his M.Sc. degree in Computing Science from Poznan University of Technology in 2002. He has been working in Poznan Supercomputing and Networking Center since 1999, he currently leads Network Research and Development Group. His research interests include broadband, optical networking and new network services. 


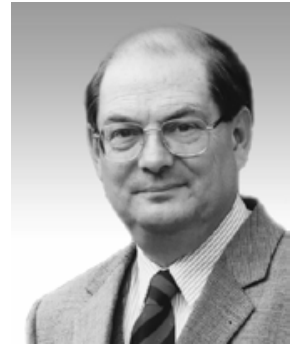

Maciej Stroiński received the Ph. D. degree in Computer Science from the Technical University of Gdańsk in 1987. Currently he is Technical Director of the Poznań Supercomputing and Networking Center. He is also lecturer in the Institute of Computing Science of the Poznań University of Technology. His research interests concern computer network protocols and management. He is author or co-author of over 100 papers in major professional journals and conference proceedings.

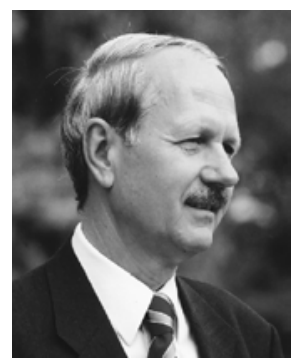

JAN Weglarz, Academician, Professor (Ph.D. 1974, Dr. Habil. 1977), in years 1978-83 Associate Professor and then Professor in the Institute of Computing Science, Poznań University of Technology, member of the Polish Academy of Sciences (PAS), Director of the Institute of Computing Science, Poznan University of Technology and its predecessors since 1987, Director of Poznań Supercomputing and Networking Center, v-ce President and Scientific Secretary of the Poznan Branch of the PAS, v-ce President of the Committee for Computer Science of the PAS, member of the State Committee for Scientific Research, Principal Editor of the Foundations of Computing and Decision Sciences, member of several editorial boards, among others Internat. Trans. Opnl. Res. and European J. Opnl. Res. Representative of Poland in the Board of Representatives of IFORS and in EURO Council (President of EURO in years 1997-98). Member of several professional and scientific societies, among others the American Mathematical Society and the Operations Research Society of America. Author and co-author of 11 monographs, 3 textbooks ( 3 editions each) and over 200 papers in major professional journals and conference proceedings. Frequent visitor in major research centers in Europe and in the USA Co-laureate of the State Award (1988) and the EURO Gold Medal (1991), laureate of the Foundation for Polish Science Award (2000). 